\title{
The Legal Grounds of Irregular Migration: A Global Game Approach
}

\author{
${ }^{1}$ ESSEC Business School and THEMA (UMR 8184), 3 Av. Bernard Hirsch, 95021 Cergy, France, E-mail: vranceanu@essec.edu \\ ${ }^{2}$ LEM-CNRS (UMR 9221), University of Lille, Cité Scientifique, 59655 Villeneuve d'Ascq Cedex, France, E-mail: \\ claire.naiditch@univ-lille1.fr
}

\begin{abstract}
:
This paper analyses the relationship between regular and irregular migration taking into account the migration network effect and the network creation mechanism. We assume that migrants can obtain a high payoff only if a critical mass of migrants is reached in the destination country. If candidates to migration receive biased signals about the economic situation of the destination country, the migrants' decision problem can be analyzed as a standard global game. Tying the quota of regular migrants to the economic performance of countries might create large discontinuities in immigration flows, with some countries attracting the bulk of irregular migrants and the other being shunned by the migrants.
\end{abstract}

Keywords: global games, irregular migration, migration policy, networks

JEL classification: F22, C72, D84

DOI: 10.1515/bejeap-2015-0259

\section{Introduction}

During the last four years, the European Union (EU) has been confronted with massive immigrant inflows mainly from Syria and Afghanistan, as well as from Africa (Eritrea, Nigeria...). According to the International Organization for Migration (IOM), more than a million migrants, most seeking refuge, crossed into Europe in 2015 , compared with just 280,000 the year before. ${ }^{1}$ In 2016 , the organization recorded 390,000 arrivals. However, exact numbers are unclear as some may have passed through borders undetected. ${ }^{2}$

This massive immigration phenomenon clearly took the European Commission (EC) and the governments of the EU member countries by surprise. After hesitating several times, on May 13, 2015 the EU agreed on the European Agenda on Migration, which, in September 2015, led the EC to adopt a "temporary relocation system". This system mainly targeted the 160,000 asylum applicants who were in Greece and Italy at that time, and a resettlement agreement targeting persons in obvious need of international protection was reached in July 2015. Distribution was calculated according to several indicators of the host country: the size of its population, its total GDP, its unemployment rate and its average number of asylum applications over the previous four years. ${ }^{3}$ The relocation plan has never been applied in its original framework, as it met a strong opposition from the Visegrad group. ${ }^{4}$ Lately, support for the relocation scheme has faded in the remaining EU countries. One year later, the numbers of relocated migrants were falling short of the initial quotas. The success of the Brexit motion in the June 2016 referendum, which should lead to the UK's exiting the EU, was to a large extent fuelled by fears of "uncontrolled" immigration. More intriguing, migrants themselves appear to be reluctant to comply with the EU relocation targets, with a large majority aiming to reach highly attractive countries such as Germany and the UK, while shunning other large countries such as France, which are no less able to welcome migrants. ${ }^{5}$

Thus, the issue of migration is gradually turning into an issue of irregular migration, which is much more difficult to address using standard tools of migratory policy such as quotas, visas and work permits. According to the IOM, "irregular migration" includes movements that take place outside the regulatory norms of the sending, transit and receiving countries. In this paper, we will adopt the perspective of the receiving countries, and refer to an "irregular migrant" as a person who "enters, stays or works in a country without the necessary authorization or documents required under immigration regulations" ${ }^{6}$ Depending on the context and the subtleties of the legal language used, these migrants are sometimes referred to as undocumented, unauthorized, illegal, clandestins (in French), etc. However, the IOM definition appears to be the most relevant to this paper, which will contrast regular (or official) flows to irregular migration flows. Irregular migrants arrive without the 
approval of the national authorities of the receiving countries, and most of the time they will try to hide from these authorities. In the case of the recent massive inflows of migrants to the EU, most enter the EU irregularly. ${ }^{7}$ Among these irregular migrants, some do not claim refugee status and thus remain irregular migrants; others proceed to their preferred destinations without complying with the Dublin Regulation (which determines the Member State responsible for the examination of asylum applications; see Achilli 2016 on Syrian asylum seekers); others apply for asylum but are not granted the refugee status and remain irregularly (either because they do not return to their places or origin, are not removed and/or are de facto non-removable; Clandestino 2009). All these migrants are thus irregular migrants.

When choosing their final destination countries, these migrants make rational decisions under imperfect information and intend to maximize their utility (Bilger, Hofmann \& Jandl 2006). Today many of the migrants who reach the EU can claim refugee status since they fled their countries of origin to protect their lives and their freedom. ${ }^{8}$ For the purpose of our analysis, we will consider that their decision involves two-stages: first, they decide to escape their home country, where their lives are under threat and travel to a neighboring safe country; second, they choose their final destination. This second-stage decision implies a comparison of expected incomes across the different possible destinations, leading the migrants to decide whether they should choose a safe but less-developed country over a more developed one, and in the latter case, they must choose the developed country (within the EU, for instance) in which they want to live. Our analyis will focus on the second-stage decision.

A substantial body of literature has been devoted to analyzing the determinants of international labor migration, from the classical wage differential motive to more sophisticated theories, emphasizing job search, risk diversification and insurance for those remaining at home, credit constraints at home for the household, family reasons, etc. (see the recent literature review by Massey (2015)). Empirical studies have shown that the probability of preferring one country over another is related to economic variables, to geography and culture, and to institutions in both the origin and the destination countries (see for instance Beine, Bertoli \& FernándezHuertas Moraga 2015; Hatton \& Williamson 2002; Mayda 2010). Several recent papers emphasize the migration network effect (Beine 2013; Beine, Docquier \& Ozden 2011; Beine \& Salomone 2013; Carrington, Detragiache \& Vishwanath 1996; Munshi 2003), defined as "the global influence exerted by migrants at destination on the flows of newcomers from their origin country" (Beine 2013). While these networks can differ in their size, structure, density and effectiveness, they all deliver "services" to newcomers, such as a culturally friendly environment and an efficient job matching mechanism, which helps migrants to find jobs. According to Beine (2013), the elasticity of bilateral migration flows related to the network effect is approximately 0.4 and increases to 0.7 for migration to OECD countries. ${ }^{9}$ The recent massive inflows of migrants to the EU - and the associated policy challenges - call for a careful investigation of the link between regular and irregular migration. This paper emphasizes the supply complementarity between regular and irregular migrants, stemming from the network effect: essentially, increasing the number of regular migrants increases the network size and thus facilitates migration for irregular migrants. Specifically, we assume that the network operates efficiently and allows to irregular migrants to get a high payoff only if a critical mass of regular and irregular migrants is reached. The next section will review the relatively scarce literature that analyses the relationship between the two types of migrants and will present existing research about the network effect in the migration context.

In our model, South-North migration is fundamentally driven by economic motives. A migrant's decisionmaking problem can thus be represented as a coordination game with strategic complementarities, where the migrant's utility is strictly positive utility only if a critical mass of migrants has made the same decision to migrate. In a destination country, there will be a number of regular migrants that match the quota set by the government. The analysis focuses on the decision of candidates to pursue irregular migration. We follow a growing body of literature that demonstrated the applications of a particular equilibrium refinement in coordination games and consider that potential migrants have heterogeneous information about the destination economy; more precisely, each of them receives a noisy idiosyncratic signal about the economic fundamentals of the destination country. Thus, beliefs are no longer common knowledge, and the problem can be analyzed as a standard "global game" as pioneered by Carlsson and Van Damme (1993) and extended to n-players by Morris and Shin (1998), Morris and Shin (2001). In most of these games, players adopt an equilibrium "switching strategy", taking one course of action if they receive a signal above a critical threshold, and another course of action if the signal is below the critical threshold. We will show that, in this model as well, there is a critical signal above which individuals decide to irregularly migrate, and below which they decide to stay in their origin country. Related to this critical signal, there is a "cut-off state of the economy" above which a critical mass of migrants (regular and irregular) arrives and creates an effective network and below which the network does not reach the critical mass to operate properly. These critical thresholds are negatively related to the number of regular migrants. Intuitively, the higher the quotas of regular migrants, the easier it is for the network to reach the critical mass even if the economic situation of the country is not very favorable; in turn, this prompts more irregular migrants to target that country. 
Our model builds on several limiting assumptions. First, the model is "static" insofar as we do not take into account the flow of information transmitted by early migrants to subsequent cohorts. As it is, it can represent of a one-shot massive migration episode essentially driven by the economic motive. Second, in the economic literature, the network effect is generally defined as the increase in value of consuming a product if many other consumers use the same product (Birke 2009). In the context of migration, the network effect would require that the individual's benefit from migration is increasing in the number of migrants choosing to live in a destination country. In this paper, we build our model considering the special case in which the positive relationship between the benefits delivered by the network and its size is discontinuous; more specifically, we assume that the network becomes operational if a critical mass of migrants is reached, and will not function properly if that critical mass is not reached. If the critical mass is reached, the migrant's payoff is assumed to be proportional to the economic fundamentals of the destination country. The model could be easily extended to a case in which the individual payoff increases with the number of migrants (Munshi 2003), insofar as this number of migrants itself depends on the economic fundamentals of the host country. Third, our analysis cannot address the exclusion issue, where, above a given number of migrants, the migrant's individual payoff would decline in the stock of migrants, for instance because the local attitude toward migrants changes from support to fear and exclusion or the migration network is diluted in the native population (Calvó-Armengol and Zenou 2005). Thus, our model makes sense only if the number of migrants is relatively low compared to the population of the destination country. Finally, in our analysis, the benefit of an effective network is delivered to irregular migrants regardless of the networks' composition of regular and irregular migrants. One can argue that regular migrants can help the arriving irregular migrants more than the other irregular migrants. This is probably true when considering that regular migrants can help newcomers finding jobs in the formal sector. On the other hand, our assumption makes sense if we agree that irregular migrants tend to find jobs in the informal sector, where the network of regular and irregular migrants might facilitate the matching process.

The following section introduces the related literature. Section 3 presents the assumptions of the model. Section 4 solves the model for the equilibrium of the game and Section 5 concludes.

\section{Related Literature}

The link between regular and irregular migration has only been studied by economists fairly recently. As will be shown, a few papers emphasize the demand perspective in the host country, and note the demand substitution between regular and irregular migrant labor. Other papers emphasize the migrant supply perspective, where regular and irregular migrants can either complement or substitute each other.

Taking a demand perspective, expanded legal possibilities for regular migration could decrease the level of irregular migration, because the demand for low-skilled immigrant labor would be filled by regular migrants instead of irregular ones. For instance, in his literature review on illegal migration from Mexico to the US, Hanson (2006) reveals that large-scale illegal migration from Mexico to the US started at the end of the Bracero program (1942-1964), which allowed US employers to hire Mexican and Caribbean workers on short-term contracts. Similarly, Ambrosini (2010) argues that more restrictive migration policies in the EU led to an increase in the number of irregular migrants (to satisfy the labor demand of host countries). This mechanism implicitly assumes that the supply of regular and irregular migrants is infinitely elastic, which is questionable. Moreover, it also assumes that firms hire irregular workers because of a shortage of regular employees. However, such firms may simply have a preference for irregular employees; increasing the number of regular migrants would then have no impact on the number of irregular migrants. In a theoretical model, Bchir (2008) demonstrates that the liberalization of the temporary movements of workers could either lead to a decrease or an increase in irregular migration, depending mainly on the quota of temporary workers and on their wages.

Turning to the supply of migrant labor, existing studies emphasize the complementarity between the two types of migrants, intermediated by some type of network effect. As already mentioned, the network effect reflects the higher facility to migrate in countries where the existing stock of migrants of the same community is large. The reasons for this positive relationship are multiple, ranging from the psychological utility of living in an environment that replicates the culture of the country of origin, to "services" delivered by the community of similar individuals, such as temporary aid, shelter or support in finding a job (Mahuteau \& Junankar 2008; Epstein \& Gang 2010). de Haas (2007) explains that migration networks not only decrease the material and psychological costs of migration but also increase the exposure of potential migrants to the relative wealth of international migrants, in turn increasing their perception of their own relative deprivation and thus their incentives to migrate. Massey et al. (1993) even show that the network effect may become so strong that the perpetuation of migration (regular as well as irregular) may become almost uncorrelated with wage differentials or employment rates in the origin and host countries. 
Several scholars argued that irregular migrants would benefit more form the network compared to regular migrants. Indeed, the latter can find jobs in the formal and informal sectors, whereas irregular migrants can only access the informal sector and often find a job within their communities, where labor networks play a crucial role (Ambrosini 2010; Boyd \& Nowak 2012). Irregular migrants usually do not benefit from social services, which implies that they rely more than regular migrants on their networks to maintain a decent standard of living (Collyer 2005; Williams 2006). Boswell (2003) notes that increasing the number of regular migrants could raise expectations about the labor market in the host country and would increase the size of the migration network, with both phenomena leading to an increase in irregular migration. Hanson (2006) mentions that Mexicans with relatives in the US appear to have higher incentives to migrate irregularly, either because they benefit from the effect of migration networks (lowering the cost of migration) or because irregular migration increases their chances of becoming regular migrants later on (increasing the benefits of migration). Bilger, Hofmann, and Jandl (2006) argue that irregular migrants are much more responsive to the network effect than regular migrants who are backed by local country policies and institutions (support income, education, job agencies, etc). Furthermore, Broeders and Engbersen (2007) suggest that irregular migrants use informal migration networks to avoid detection by the state and to remain in the shadows of ethnic communities. Finally, irregular migrants benefitting from large networks have a higher probability of settling regularly (Hagan 1998), which in turn increases their earning prospects.

These studies focus on the consequences of an existing network on the decision to migrate (regularly or irregularly). This paper aims to contribute to this literature by emphasizing the network creation process and the migrants' coordination decision problem, taking into account the heterogeneous structure of information. To our knowledge, this is the first time that the global games analysis (Morris and Shin 1998 ; Morris and Shin 2001) is applied to the migration problem.

\section{The Model: Main Assumptions}

We study the dynamics of migration between two countries, a rich country from the North and a poorer country from the South. The decision to migrate from South to North is driven by economic reasons, with individuals aiming to maximize their expected payoff. ${ }^{10}$ The North chooses the numbers of regular migrants $L$, according to its migratory policy. Because these regular migrants reach the North through an official programme, they will have access to jobs and social security. Our analysis will focus on the fate and decisions of candidates for irregular migration, which are excluded from the regular migration programme. Let $S$ be the pool of candidates for irregular migration, which, for simplicity, is assumed to be constant. Candidates to irregular migration have similar personal characteristics; in particular, they are risk-neutral individuals. ${ }^{11}$ Let us denote by $\theta$ the state of the fundamentals of the North economy, with $\theta \in[0,1]$, with 0 being representative of a depressed economy, and 1 of a booming economy. The better the economic situation, the higher $\theta$. This state of the economy is a random variable with a known statistical distribution.

To introduce the network effect affecting the decision of irregular migrants, we assume, following Massey et al. (1993), that there is a critical number of migrants $V$, above which the network is created and operates properly. To rule out a trivial outcome, we consider that $V<S$. The condition for the network to operate properly is thus:

$$
M+L \geq V
$$

Let us define by $m=M / S$ the frequency of actual migration in the mass of candidates to irregular migration, with $m \in[0,1]$. Then the network creation condition becomes:

$$
m S+L \geq V \Leftrightarrow m+l \geq v
$$

with $l=L / S$ and $v=V / S$, with $v<1$.

We assume that the migration policy in the North can be expressed by a policy rule applied to regular migration. A plausible policy reaction function that allows for simple future calculations is $l=\gamma \theta$. According to this function, the number of legal migrants (relative to $S$ ) is an increasing function in $\theta$, representing the economic fundamentals of the North (Chiswick and Hatton 2003). The parameter $\gamma \in[0,1]$ captures the "openness" of migration policies in the North. The network creation condition can be written as:

$$
m+\gamma \theta \geq v
$$


The possible payoffs for an irregular migrant depend on his decision and the decisions of the other potential migrants, which ultimately allow the network to reach the critical size. If he migrates and the network operates properly, an irregular migrant can earn a positive income $R$, otherwise he earns a subsistence amount that will be normalized to zero. If he decides to stay, he earns a certain payoff $s$. These payoffs can be summarized as:

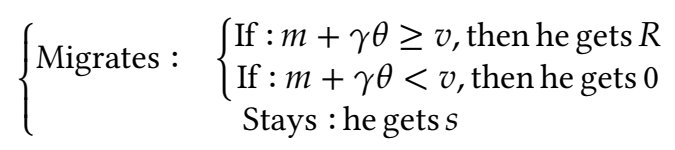

The migration payoff $R$ is higher than $s(R>s)$ and is increasing in the fundamentals of the host economy, $R=R(\theta)$.

To obtain closed form solutions, we need to be more specific about the information structure of the problem. We assume that the "fundamentals of the economy" variable is uniformly distributed in the $[0,1]$ interval, i.e : $\theta \rightsquigarrow$ unif $[0,1]$.

Finally, potential migrants observe the realized economic fundamentals of the North with an individual specific-bias. A migrant $i$ will thus observe the following signal: $x_{i}=\theta+e_{i}$; we will consider that signals are also uniformly distributed across migrants, with $e_{i} \rightsquigarrow$ unif $[-\epsilon, \epsilon]$, with $\epsilon>0$.

\section{The Equilibrium}

In a perfect information setting (where $\theta$ would be common knowledge), we can distinguish between two cases. If $l=\theta \gamma \geq v$, the network is created by regular migrants regardless of irregular migrants, so any potential candidate for irregular migration should migrate, because he/she would obtain the high payoff $R$. In equilibrium all candidates for irregular migration do migrate.

For $l=\theta \gamma<v$, this coordination game with strategic complementarity features multiple equilibria, a standard outcome of such coordination games. The first is the payoff-dominant Nash equilibrium. If all potential migrants leave their origin countries $(m=1)$, then $l+m \geq 1>v$; the network is created and all irregular migrants obtain $R$. An individual who would unilaterally deviate and choose the "stay" strategy would regret it, because $s<R$. However, because this payoff-dominant equilibrium relies on the decision to migrate by all other candidates for migration, it is subject to "strategic uncertainty". Should candidates for migration fail to coordinate their actions (migrate), they could end up with a zero payoff. In the second Nash equilibrium, candidates for irregular migration coordinate with regard to the "stay" strategy $(m=0)$; they all obtain the certain positive payoff $s$ without incurring the strategic risk. The individual who would deviate unilaterally and migrate would obtain zero, because the critical threshold $(v)$ is not reached.

While multiple equilibria might have an appeal to theorists, they have little utility for policy analysis insofar as one cannot predict the consequences of changes in policy parameters if he cannot define what the equilibrium of the system is. One relevant equilibrium refinement for coordination games with strategic complementarities was introduced by Carlsson and Van Damme (1993) in the 2-player case and was extended to the n-player case by Morris and Shin (1998), Morris and Shin (2001). In their analysis, information is "heterogeneous" - agents do not observe the fundamentals of the economy $(\theta)$, but rather receive a biased signal of its state, with each individual receiving his own signal. In this context, beliefs are no longer common knowledge and agents cannot perfectly coordinate their actions. This "small" change in the structure of information can eliminate the multiplicity of equilibria and replace it by a single equilibrium of a special form. Indeed, these problems present a so-called threshold equilibrium defined by a unique critical signal $x^{*}$ around which individuals switch strategies.

In the migration context, it can be shown that there is a unique critical signal $x^{*}$ such that individuals receiving a signal $x \geq x^{*}$ migrate (irregularly), and those receiving $x<x^{*}$ stay. Related to this signal, there is a unique cut-off state of the economy $\theta^{*}$ below which the number of residents of the South who decide to migrate irregularly is too small to reach the critical threshold $v$, and vice-versa. For the sake of parsimony we do not recall here the formal proof of existence of the threshold equilibrium as developed by Morris and Shin (2001) which proceeds by successive elimination of dominated strategies. Instead, we first assume that these thresholds exist and prove that they are unique. The resolution steps follow Atkeson (2001) .

\subsection{The Cut-Off State of the Economy}

According to our assumptions regarding the distribution of the errors, when Nature draws a state of the economy $\theta$, signals $x_{i}$ will be uniformly distributed on $[(\theta-\epsilon),(\theta+\epsilon)]$ among the population of potential migrants. ${ }^{12}$ For any given critical signal $x^{*}$, the frequency of irregular migrants is an increasing function in $\theta$ : 


$$
m(\theta)=\operatorname{Pr}\left[x_{i} \geq x^{*} \mid \theta\right]=\frac{1}{2 \epsilon}\left[(\theta+\epsilon)-x^{*}\right]
$$

We define the cut-off state of the economy $\theta^{*}$ as the fundamentals' value for which the critical mass of migrants $v$ is reached; that is, if $\theta \geq \theta^{*}$, then $\gamma \theta+m \geq v$ (the migration episode succeeds) and vice-versa.

Because $m$ is an increasing function of $\theta$, the implicit definition of the cut-off state of the economy $\theta^{*}$ for a given $x^{*}$ is:

$$
m\left(\theta^{*}\right)+\gamma \theta^{*}=v \Leftrightarrow x^{*}-\theta^{*}+\epsilon=2 \epsilon\left(1-v+\gamma \theta^{*}\right)
$$

\subsection{The Critical Signal}

We now look for the critical signal $x^{*}$, characteristic of the individual who is indifferent between staying and migrating. According to the definition of $\theta^{*}$, the migration episode succeeds in creating the efficient network for $\theta \geq \theta^{*}$, and fails if $\theta<\theta^{*}$. The indifferent migrant's expected gain is as follows:

$$
E\left[R \mid \theta^{*}\right]=\int_{\theta^{*}}^{\theta^{S}} R(\theta) f\left(\theta \mid x^{*}\right) d \theta
$$

where $f\left(\theta \mid x^{*}\right)$ is the ex-post distribution of $\theta$ for the individual with signal $x^{*}$ and $\theta^{S}$ is the upper bound of the ex-post distribution.

Given the assumption of the uniform distribution of the signals, for the migrants who receive the signal $x^{*}$, the ex-post distribution of $\theta$ is unif $\left[\left(x^{*}-\epsilon\right),\left(x^{*}+\epsilon\right)\right]$. In this case, the ex-post density is $f\left(\theta \mid x^{*}\right)=1 /(2 \epsilon)$ and the upper bound is $\left(x^{*}+\epsilon\right)$. Thus, we can write the expected gain of the indifferent individual as follows:

$$
E\left[R \mid \theta^{*}\right]=\frac{1}{2 \epsilon} \int_{\theta^{*}}^{\left(x^{*}+\epsilon\right)} R(\theta) d \theta
$$

To obtain an analytical solution, we make the simplifying assumption according to which the migrant's payoff in the event of the success of the migration episode is linearly increasing in $\theta$ :

$$
R(\theta)=s+a \theta
$$

with $a>0$ a parameter.

Under this assumption, the expected gain can be calculated as follows:

$$
E\left[R \mid \theta^{*}\right]=\frac{1}{2 \epsilon}\left[s \theta+0.5 a \theta^{2}\right]_{\theta^{*}}^{\left(x^{*}+\epsilon\right)}=\frac{1}{4 \epsilon}\left(x^{*}+\epsilon-\theta^{*}\right)\left[2 s+a\left(x^{*}+\epsilon+\theta^{*}\right)\right]
$$

The indifference condition $s=E\left[R \mid \theta^{*}\right]$ implicitly defines the critical signal $x^{*}$ for a given $\theta^{*}$ :

$$
\frac{1}{4 \epsilon}\left(x^{*}-\theta^{*}+\epsilon\right)\left[a\left(x^{*}-\theta^{*}+\epsilon\right)+2\left(a \theta^{*}+s\right)\right]=s
$$

An individual $i$ who gets a signal $x_{i}>x^{*}$ would expect a gain higher than $s$, and vice-versa.

\subsection{The Threshold Equilibrium}

We can solve the system of two eqs. (6) and (11) and two unknowns $\left(\theta^{*}, x^{*}\right)$ for the joint (equilibrium) solution. In so doing, we replace $x^{*}-\theta^{*}+\epsilon=2 \epsilon\left(1-v+\gamma \theta^{*}\right)$ in eq. (11) to obtain a quadratic equation defining $\theta^{*}$ :

$$
\left(1-v+\gamma \theta^{*}\right)\left[a \epsilon\left(1-v+\gamma \theta^{*}\right)+\left(a \theta^{*}+s\right)\right]=s
$$


The equilibrium cut-off state of the economy depends on the parameters of the problem: $\theta^{*}=\theta^{*}(a, s, v, \gamma, \epsilon)$.

The eq. (12) has at most one positive root, and this requires that $\epsilon \leq \frac{s v}{a(1-v)^{2}}$, i.e., if the "noise" in the signals is not too large. The solution is:

$$
\theta^{*}=\frac{\sqrt{[\gamma s+a(1-v)]^{2}+4 \gamma s a(v+\epsilon \gamma)}-[\gamma s+a(1-v)(1+2 \epsilon \gamma)]}{2 \gamma a(1+\epsilon \gamma)}
$$

Eq. (6) then allows us to determine the critical signal $x^{*}=x^{*}(a, s, v, \gamma, \epsilon)$. The actual frequency of irregular migrants $m$ (in the population $S$ ) is a function of the actual $\theta$ and the equilibrium critical signal $x^{*}: m(\theta)=$ $\operatorname{Pr}\left[x_{i} \geq x^{*} \mid \theta\right]=\left\{\max \left(0, \frac{1}{2 \epsilon}\left[(\theta+\epsilon)-x^{*}\right]\right) ; \min \left(1, \frac{1}{2 \epsilon}\left[(\theta+\epsilon)-x^{*}\right]\right)\right\}$.

If the noise in the information flow is high, more precisely if $\epsilon>\frac{s v}{a(1-v)^{2}}$, then eq. (12) has no positive root. Thus, whatever $\theta \in[0,1]$ we have $\theta>\theta^{*}$ : whatever the state of the economy the critical migration threshold is reached; $m=1$, a large flow of irregular migration has to be expected.

As shown by Morris and Shin $(1998,2001)$, global games present an interesting limit case when the variance of private information tends to zero without fully suppressing the imperfection of information (see also Heinemann, Nagel \& Ockenfels 2009). For $\epsilon \rightarrow 0$, the equilibrium cut-off state of the economy can be written as follows:

$$
\left[\theta^{*}\right]_{\epsilon \rightarrow 0}=\frac{\sqrt{[\gamma s+a(1-v)]^{2}+4 \gamma s a v}-[\gamma s+a(1-v)]}{2 \gamma a}>0
$$

and the critical signal becomes $x^{*}=\theta^{*}$. In this special case, the threshold equilibrium still prevails; the migration decision depends on the economic situation of the host country (almost known to the migrants): if $\theta \geq \theta^{*}$, all candidates for irregular migration receive signals above $x^{*}$ so $m=1$, and if $\theta<\theta^{*}, m=0$.

\subsection{Properties of the Equilibrium}

In what follows, let us focus on the most interesting case where $\epsilon$ is small enough, such as $\theta^{*}>0$ and $\left(x^{*}-\epsilon\right)>0$. The set of $\theta$ for which $0 \leq m(\theta) \leq 1$ is the interval $\left[\left(x^{*}-\epsilon\right),\left(x^{*}+\epsilon\right)\right]$; on this interval, $m$ is a linear, increasing function in $\theta$. For $\theta$ lying outside of the interval $\left[\left(x^{*}-\epsilon\right),\left(x^{*}+\epsilon\right)\right]$, candidates for irregular migration will either all migrate or all stay. The smaller $\epsilon$ is, the narrower this interval. When $\epsilon$ tends to zero, the regime shift from $m=0$ to $m=1$ is the most brutal, or the model presents the strongest "discontinuity".

For $\theta^{*}>0$, when Nature choses $\theta<\theta^{*}$, the high migration payoff is not reached, and individuals who get a signal above the critical signal and migrate irregularly will end up in a worse situation compared to staying in their origin country. In this case, the chances that the critical migration threshold $(v)$ is reached are measured by $\operatorname{Pr}\left[\theta>\theta^{*}\right]=1-\theta^{*}$.

We can now study how the cut-off state of the economy and thus the tendency to attract irregular migrants varies with the parameters of the model, particularly with the noise of the signals and the openness to migration. The total derivative of expression (12) allows us to see that $\theta^{*}$ is decreasing in $\epsilon, \gamma$ and $a$, and increasing in $v$ :

$$
\begin{aligned}
\frac{d \theta^{*}}{d \epsilon} & =-\frac{a\left[1-v+\gamma \theta^{*}\right]^{2}}{a(1+2 \epsilon \gamma)\left(1-v+\gamma \theta^{*}\right)+\gamma\left(a \theta^{*}+s\right)}<0 \\
\frac{d \theta^{*}}{d \gamma} & =-\frac{\left[2 a \epsilon\left(1-v+\gamma \theta^{*}\right)+\left(a \theta^{*}+s\right)\right] \theta^{*}}{a(1+2 \epsilon \gamma)\left(1-v+\gamma \theta^{*}\right)+\gamma\left(a \theta^{*}+s\right)}<0 \\
\frac{d \theta^{*}}{d a} & =-\frac{\left(1-v+\gamma \theta^{*}\right)\left[\epsilon\left(1-v+\gamma \theta^{*}\right)+\theta^{*}\right]}{a(1+2 \epsilon \gamma)\left(1-v+\gamma \theta^{*}\right)+\gamma\left(a \theta^{*}+s\right)}<0 \\
\frac{d \theta^{*}}{d v} & =\frac{2 a \epsilon\left(1-v+\gamma \theta^{*}\right)+\left(a \theta^{*}+s\right)}{a(1+2 \epsilon \gamma)\left(1-v+\gamma \theta^{*}\right)+\gamma\left(a \theta^{*}+s\right)}>0 \\
\frac{d \theta^{*}}{d s} & =\frac{v-\gamma \theta^{*}}{a(1+2 \epsilon \gamma)\left(1-v+\gamma \theta^{*}\right)+\gamma\left(a \theta^{*}+s\right)}>0
\end{aligned}
$$

First, the critical cut-off state of the economy is decreasing in the noise of the signals. Thus, the higher the noise, the higher the range of $\theta$ leading to high irregular migration. In the model, this can be easily rationalized. When 
noise is high in a given state of the economy, more candidates for migration will receive high signals and decide to migrate. In turn, this higher flow of migrants guarantees that the critical network threshold is reached even if the fundamentals of the economy are poorer. In the current EU migration crisis, one important culprit is the degree of migrants' misinformation about the opportunities each countries can offer, misinformation sometimes fuelled by traffickers (Schloenhardt 2002 studying the smuggling of migrants in the Asia-Pacific region). For this reason, several EU countries (such as Denmark and Norway) have financed information campaigns in migrants' origin countries. ${ }^{13}$ Second, if the host country becomes more open to regular migrants ( $\gamma$ increases), the critical threshold $v$ can be reached more easily, and the chances that the migration episode for irregular migrants succeeds also increase. Thus, an increase in $\gamma$ would both increase the flow of regular migrants and the attractiveness of the country for irregular migrants.

In line with intuition, if the marginal benefit of migration $(a)$ increases, chances that the migration episode succeeds increase; if the critical migration threshold $(v)$ is increased, chances that the migration episode succeeds decline. The sign of $d \theta^{*} / d s$ is the same as the sign of $\left(v-\gamma \theta^{*}\right)$, which must be positive. ${ }^{14}$ While a higher $s$ increases both the payoff in the "stay" equilibrium $(s)$ and the high payoff in the risky "migrate" equilibrium $(R(\theta)=s+a \theta)$, the former effect applying to the whole mass of candidates for irregular migration appears to take over the latter effect.

Finally, all other variables kept constant, $M$ and $L$ vary jointly depending on the shocks to economic fundamentals of the destination country (realized values of $\theta$ ). We recall the expressions of the numbers of regular and irregular migrants, $L=\gamma \theta S$ and $M=m(\theta) S$. A large $\theta$ would prompt authorities in the North to accept more regular migrants, $d L / d \theta>0$ and will also raise the proportion of irregular migrants, thus $d M / d \theta>0$. In this model, regular and irregular migration have a positive covariance, driven by the random realization of $\theta$. One important initial assumption consisted in considering the number of candidates to irregular migration $S$ as constant. Implicitly, we assumed that candidates to illegal migration do not qualify for the regular migration policy of the North. In an alternative, more complex model, any additional regular migrant might reduce the number of potential irregular migrants by one. In this case, a higher proportion of migrants would apply to a reduced pool of potential irregular migrants, with a positive or a negative effect on the total number of irregular migrants.

\section{Conclusion}

In this paper, we build a small model to analyze the interaction between the number of regular migrants as resulting from the migration policy of a "rich" host country and the inflow of irregular migrants. This analysis acknowledges the essential role of the migrant network on the decision to migrate irregularly as revealed by several studies surveyed in the Introduction. It contributes to this literature by analyzing the network creation process in the context of migrants' heterogeneous information about the host country. The decision problem of potential migrants is formalized as an n-player global game, in line with the classical analysis by Morris and Shin (1998) and Morris and Shin (2001). We solve the migrant coordination game for the threshold equilibrium. Like many other global games, this one presents an equilibrium cut-off state of the economy above which the "rich" country will be subject to high irregular migration, and below which irregular migrants will not target the country.

Under the assumption of a constant pool of candidates to irregular migration, the analysis revealed a positive correlation between the number of regular migrants and the number of irregular migrants, driven by fluctuations in the economic fundamentals variable. It further shows that a policy allowing high numbers of regular migrants can make a country more appealing to irregular migrants even if the economic outlook is less favorable. Finally, the model shows that reducing the information bias of potential migrants would reduce the probability of attracting substantial irregular migration.

In the context of the recent EU challenge of massive immigration flows, the question of how the quota of regular migrants (including asylum seekers and refugees) is determined becomes a crucial issue because it also determines the number of irregular migrants. Irregular migrants, given the very definition of the concept, cannot be allocated because they are not observed as such and are not supposed to exist.

Our analysis has shown that simply tying the number of regular migrants to the economic outlook of a country can entail large discontinuities in the inflows of irregular migrants, with countries with a good economic outlook attracting most of the migrants, while countries with a poor economic outlook are shunned. This is probably one original finding of our analysis, that the frontier between what makes a country attractive/unattractive for massive irregular migration relies on small variations in exogenous variables such as the state of the economy or the quota of legal migration. This positive/negative amplification results from the 
income factor compounding its effect on the network effect, which is the consequence of the threshold equilibrium. The higher the precision of the signals, the stronger the discontinuities in the migration flows.

When deciding how many regular migrants (asylum seekers or refugees) it allocates to a country, the EC must take into account the indirect consequences of this policy on the number of irregular migrants this country will attract, for instance by providing material support to these countries that goes beyond support for regular migrants only. In countries with a modest economic outlook, high irregular migration may be the outcome of high noise in the signals; the EU could also finance information campaigns in migrants' origin countries, informing them about the true conditions of irregular migrants in the destination country, and encouraging them to follow only the regular channels to migration.

\section{Acknowledgement}

The authors are grateful to two anonymous referees as well as participants to the $5^{\text {th }}$ Lille-Ghent Workshop in Economics, Gand (Belgium), Dec. 2015, the Annual Conference of the International Trade and Finance Association, Sarasota (Florida, USA) Mai 2015, Séminaire Equippe - Economie, Lille (France), Dec. 2014, the Wim Meeusen Workshop, Santander (Spain), Oct. 2014, for their suggestions and comments that helped them to improve the quality of the paper. Radu Vranceanu carried out this research within the framework of the LABEX MME-DII (labex-mme-dii.u-cergy.fr/).

\section{Notes}

\footnotetext{
${ }^{1}$ The International Organization for Migration defines an international migrant as any person who is moving or has moved across an international border, regardless of (1) the person's legal status; (2) whether the movement is voluntary or involuntary; (3) what the causes for the movement are; or (4) what the length of the stay is. The Convention relating to the Status of Refugees (1951) as modified by the 1967 Protocol defines a refugee as a person who "owing to a well-founded fear of persecution for reasons of race, religion, nationality, membership of a particular social group or political opinions, is outside the country of his nationality and is unable or, owing to such fear, is unwilling to avail himself of the protection of that country". A person awaiting a decision on the application for refugee status under relevant international and national instruments is an asylum seeker.

${ }^{2}$ See the website of the International Organization for Migration at www.iom.int.

${ }^{3}$ See European Commission - Press release, "Relocation and resettlement: Increased efforts on resettlement and relocation must be sustained", Brussels, 15 June 2016, http:/ / europa.eu/rapid/press-release ${ }_{I} P-16-2178$ $e^{\text {n.htm }}$

${ }^{4}$ Czech Republic, Hungary, Poland and Slovakia.

${ }^{5}$ See for instance: "The dispensable French", The Economist, November 7, 2015, http://www.economist.com/news/europe/21677987-france-has-less-and-less-influence-eu-and-fears-use-what-it-still-has-dispensable. See also "Refugees shun France, land of red tape, unemployment and poor housing", The Telegraph, September 21, 2015, http://www.telegraph.co.uk/news/worldnews/europe/france/11880391/Refugees-shun-France-land-of-red-tape-unemployment-and-poor-housing.html.

${ }^{6}$ As defined by the IOM, accessed on June 02, 2016: http:/ / www.iom.int/key-migration-terms.

7"Migrant crisis: Migration to Europe explained in seven charts", BBC, March 4, 2016, http://www.bbc.com/news/world-europe34131911 and "What happens to failed asylum seekers?" BBC News Magazine, August 13, 2015, http://www.bbc.com/news/magazine33849593.

${ }^{8}$ The Organization for African Unity Convention of 1969 expanded the definition of refugees to include not only individuals subject to persecution, but also every person who "owing to external aggression, occupation, foreign domination, or events seriously disturbing public order...is compelled to leave...to seek refuge in another place outside his country of origin or nationality."

${ }^{9}$ As explained by Beine (2013), the measures of diaspora in empirical studies are often underestimated since most of the time, they include only regular and permanent adult migrants.

${ }^{10}$ Thus the model applies to asylum seekers, who are considering their second stage decision, where they must choose between a country close to their origin country, safe but not developed, and a developed country farther away. It also applies to migrants who already reached the EU and are choosing their destination country. In the context of these decisions, we consider asylum seekers' motives to leave as essentially economic.

${ }^{11}$ This simplifying assumption allows us to provide an analytical solution. The problem could be extended to allow for risk-averse or risk seeking migrants by including a Von Neumann - Morgenstern utility function. This more general but also more complex problem would entail similar conclusions to those obtained under the assumption or risk-neutrality.

${ }^{12} \mathrm{We}$ focus here on the case where $\epsilon$ is small. In the general case, the support of the distribution is unif $[\max [0,(\theta-\epsilon)], \min [(\theta+\epsilon), 1]]$.

13"Norway launches anti-refugee advertising campaign", The Telegraph, November 4, 2015, http://www.telegraph.co.uk/news/worldnews/europe/norway/11975535/Norway-launches-anti-refugee-advertising-campaign.html, and "Denmark puts ad in Lebanese newspapers: Dear refugees, don't come here", The Washington Post, September 7, 2015, https://www.washingtonpost.com/news/worldviews/wp/2015/09/07/denmark-places-an-advertisement-in-lebanese-newspapers-dear-refugees-dont-come-here/.

${ }^{14}$ If $l=\gamma \theta^{*}>v$, legal migration suffices to create the network, thus all candidates for irregular migration should migrate regardless of their signals.
} 


\section{References}

Achilli, L. 2016. “Tariq al-Euroba: Displacement Trends of Syrian Asylum Seekers to the EU.” In MPC RR 2016/01, Robert Schuman Centre for Advanced Studies, San Domenico di Fiesole (FI). European University Institute.

Ambrosini, M. 2010. “Migrants dans l'ombre. Causes, dynamiques, politiques de l'immigration irrégulière." Revue Européenne des Migrations Internationales 26 (2): 7-32.

Atkeson, A. A. Comment on Morris and Shin: Rethinking Multiple Equilibria in Macroeconomic Modeling. NBER Macroeconomics Annual 2000 2001:162-171. VOL 151.

Beine, M. 2013. “The Network Effect in International Migration." CESifo DICE Report 1/2013 (March).

Beine, M., S. Bertoli, and ]. Fernández-Huertas Moraga. 2015. "A Practitioners' Guide to Gravity Models of International Migration." The World Economy 39 (4): 1-17.

Beine, M., F. Docquier, and C. Ozden. 2011. “Diasporas.” Journal of Development Economics 95: 30-41.

Beine, M., and S. Salomone. Network Effect in International Migration: Does Education Matter More Than Gender? Scandinavian Journal of Economics 2013:354-380. 1152.

Bilger, V., M. Hofmann, and M. Jandl. 2006. “Human Smuggling as a Transnational Service Industry: Evidence from Austria." International Migration 44 (4): 59-93.

Birke, D. 2009. "The Economics of Networks: A Survey of the Empirical Literature." Journal of Economic Surveys 23 (4): 762-793.

Bchir, M. H. 2008. "The Effect of Mode 4 Liberalization on Illegal Immigration." Economic Modelling 25: 1051-1063.

Boswell, C. European Migration Policies in Flux - Changing Patterns of Inclusion and Exclusion. The Royal Institute of International Affairs, Chatham House Papers, Blackwell Publishing, 2003.

Boyd, M., and ]. Nowak. Social Networks and International Migration. In: Martiniello M., and Rath J., editors. An Introduction to International Migration Studies - European Perspectives Amsterdam University Press, 2012.

Broeders, D., and G. Engbersen. 2007. “The Fight Against Illegal Migration - Identification Policies and Immigrants' Counterstrategies." American Behavioral Scientist 50 (12): 1592-609.

Calvó-Armengol, A., and Y. Zenou. 2005. "Job Matching, Social Network and Word-of-Mouth Communication." Journal of Urban Economics 57 : 500-522.

Carlsson, H, and E Van Damme. 1993. “Clobal Games and Equilibrium Selection.” Econometrica 61 (5): 989-1018.

Carrington, W. J., E. Detragiache, and T. Vishwanath. 1996. “Migration with Endogenous Moving Costs.” The American Economic Review 86 (4): 909-930.

Chiswick, B., and T. J. Hatton. 2003. “International Migration and the Integration of Labor Markets.” In Globalization in Historical Perspective., edited by M. D. Bordo, A. M. Taylor, and J. G. Williamson University of Chicago Press.

Clandestino. Pathways into Irregularity: The Social Construction of Irregular Migration. Clandestino Research Project-Counting the Uncountable: Data and Trends across Europe 2009; Comparative Policy Brief-Pathways and Policies, European Commission.

Collyer, M. 2005. "When Do Social Networks Fail to Explain Migration? Accounting for the Movement of Algerian Asylum-Seekers to the UK." Journal of Ethnic and Migration Studies 31 (4): 699-718.

Epstein, G. S., and I. N. Gang. 2010. “Migration and Culture." In Migration and Culture., edited by C.S. Epstein, and I.N. Ganf, 1-21. Bingley, UK: Emerald Group Publishing.

de Haas, H. 2007. “Turning the Tide? Why Development Will not Stop Migration." Development and Change 38 (5): 819-841.

Hagan, J. M. 1998. “Social Networks, Gender, and Immigrant Incorporation: Resources and Constraints." American Sociological Review 63 (1): $55-67$.

Hanson, G. H. 2006. “Illegal Migration from Mexico to the United States.” Journal of Economic Literature 44 (4): 869-924.

Hatton, T. J., and J. G. Williamson. 2002. “What Fundamentals Drive World migration?” NBER Working Paper (9159).

Heinemann, F., R. Nagel, and P. Ockenfels. 2009. “Measuring Strategic Uncertainty in Coordination Cames.” Review of Economic Studies 76 (1): 181-221.

Mahuteau, S., and P. R. Junankar. 2008. “Do Migrants Cet Cood Jobs in Australia? The Role of Ethnic Networks in Job Search.” Economic Record 84 (S1): 15-30.

Massey, D.S. 2015. “Migration, Theory of." In International Encyclopedia of the Social \& Behavioral Sciences., edited by Neil ]. Smelser, and Paul B. Baltes, 2 466-470. Amsterdam: Elsevier.

Massey, D. S., J. Arango, G. Hugo, A. Kouaouci, A. Pellegrino, and J. E. Taylor. 1993. “Theories of International Migration: A Review and Appraisal." Population and Development Review 19 (3): 431-466.

Mayda, A. 2010. “International Migration: A Panel Data Analysis of the Determinants of Bilateral Flows." Journal of Population Economics 23 (4): 1249-74.

Morris, S., and H.S. Shin. 1998. “Unique Equilibrium in a Model of Self-Fulfilling Currency Attacks.” American Economic Review 88 (3): $587-597$.

Morris, S., and H. S. Shin. Rethinking Multiple Equilibria in Macroeconomic Modeling. NBER Macroeconomics Annual 2000 VOL 15, 2001:139-161.

Munshi, K. 2003. “Networks in the Modern Economy: Mexican Migrants in the US Labor Market.” The Quarterly Journal of Economics 118 (2): 549-599.

Schloenhardt, A. 2002. "Organized Crime and Migrant Smuggling: Australia and the Asia-Pacific." In Research and Public Policy Series, 44. Canberra: Australian Institute of Criminology.

Williams, L. 2006. "Social Networks of Refugees in the United Kingdom: Tradition, Tactics and New Community." Journal of Ethnic and Migration Studies 32 (5): 865-879. 